\title{
A STABILITY- INDICATING HPTLC METHOD FOR QUANTIFICATION OF ENALAPRIL MALEATE IN TABLETS
}

\author{
SIGRID C. MENNICKENT ${ }^{\prime}$; CRISTIAN RIVAS ${ }^{1}$; MARIO A. VEGA ${ }^{2}$; MARTA G. DE DIEGO ${ }^{1}$ \\ ${ }^{I}$ Department of Pharmacy, Faculty of Pharmacy, University of Concepción, P.O. Box 237, Concepción, Chile. \\ ${ }^{2}$ Department of Bromatology, Nutrition and Dietetic, Faculty of Pharmacy, University of Concepción, P.O. Box 237, Concepción, Chile.
}

(Received: October 5, 2012 - Accepted: December 14, 2012)

\begin{abstract}
A stability- indicating high performance thin layer chromatographic (HPTLC) method was developed and validated for the determination of enalapril maleate in tablets.

Chromatographic separation was achieved on precoated silica gel F 254 HPTLC plates using a mixture of 1-buthanol, glacial acetic acid and water (12:3:5, $\mathrm{v} / \mathrm{v}$ ) as a mobile phase. Quantitative analysis was carried out at a wavelength of $207 \mathrm{~nm}$. The method exhibitied an adequate linearity $(\mathrm{r}=0.998)$, selectivity, precision and accuracy.

Enalapril was subjected to oxidative, hydrolytic, thermal and photolytic stress conditions, and was found degradation significantly in basic stress condition only, during the time of the study. The degradation products were well resolved from main peak, proving the stability-indicating power of the method.

This method was successfully applied for quantitative analysis of enalapril maleate in tablets. Therefore, the method is suitable for quantitative determination and the stability studies of enalapril maleate in tablets.
\end{abstract}

Key words: enalapril, stability- indicating method, HPTLC, tablets.

\section{INTRODUCTION}

Stress testing is an important part of drug development process because it can help to establish the degradation pathways and the intrinsic stability of the molecule and validate the stability indicating power of the analytical procedures used. Chemical degradation may results in a loss of potency or an increase in drugs toxicity, so that clinical use of a medicine must be unacceptable if the degradation is relatively great ${ }^{1}$.Stress testing helps to anticipate the behaviour of the drug substance when using it as a drug produt. The nature of the stress testing depends on the individual drug substance and the type of drug product involved. Stress testing includes the effect of temperatures and other appropriate conditions such as humidity, light exposition, an others. ${ }^{1-4}$

Enalapril is an angiotensin-converting (ACE) inhibitor. Enalapril is a prodrug and has little pharmacological activity until hydrolyzed in the liver to enalaprilat. Enalapril is the ethylester of enalaprilat. Figure 1 and Figure 2 shows the chemical structures of both compounds.

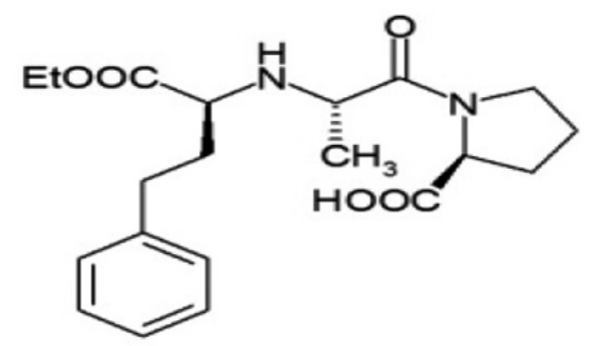

Figure 1. Chemical structure of enalapril.

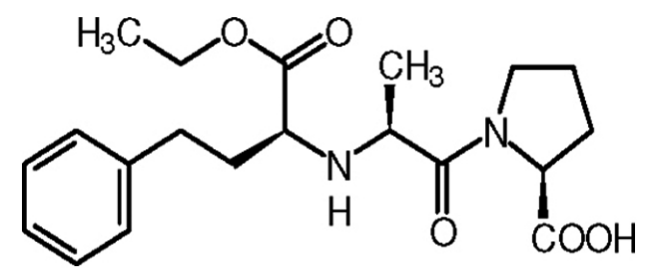

Figure 2. Chemical structure of enalaprilat.
Enalapril is used alone or in combination with other classes of antihypertensive agents for the management of hypertension.

Enalapril maleate alone or in fixed combination with felodipine or hydrocholorotiazide is administered orally.

Enalapril maleate, unlike enalaprilat, is well absorbed following oral administration. Although enalaprilat is a more potent ACE inhibitor than enalapril, it is poorly absorbed from the GI tract because of his high polarity, with only about $3 \%-12 \%$ of an orally administered dose being absorbed. .Approximately $55 \%-75 \%$ of an oral dose on enalapril maleate is rapidly absorbed from the GI tract in healthy individuals and hypertensive patients.

It is reported that enalapril drug substance or pharmaceutical preparation degrades to two major degradation products; enalaprilat and diketopiperazine derivative (DKP), under different storage conditions. ${ }^{5-7}$

The reported methods for quantitative determination of enalapril in pharmaceutical samples, including official method, 2 are by liquid chromatography with UV detection, ${ }^{8-9}$ by spectroscopy, ${ }^{10-11}$ and by polarography. ${ }^{12}$

Although some high performance thin layer chromatography (HPTLC) methods were found in literature for quantitative determination of this drug in pharmaceutical samples, ${ }^{13-15}$ none of these HPTLC methods were stabilityindicating.

High performance of HPTLC it is due to it fastness, solvent econnomy and high throughput of samples. Chromatography of samples simultaneously with standards it is another advantage, allowing to run up to 60 chromatographies simultaneously (both sides of the plate). Sensitivity of HPTLC it is normally in the range of nanograms in absorbance and picograms in fluorescence mode.

This paper deals with develop and validate a simple stability-indicating HPTLC method for enalapril maleate, and with the determination of its chemical stability under various ICH stress testing.

\section{EXPERIMENTAL}

\section{Material}

Instrumentation

HPTLC system: Spectrodensitometer Scanner 3 (Camag, Muttenz, Switzerland), equipped with software winCATS 1.4.2 (Camag). Band application device: ATS 3 automatic (Camag); twin trough chromatographic chamber (Camag) 10x10 $\mathrm{cm}$ and 20x10 cm; and HPTLC glass backed plates $10 \times 10 \mathrm{~cm}$ and 20x10 cm, pre-coated with silica gel F 254 (Merck, Darmstadt, Germany).

Reagents and chemicals

Standard of enalapril maleate was obtained from Sigma-Aldrich (St.Louis, 
MO, USA). Standard of enalaprilat was obtained from USP (Rockville, MD, USA). 1-buthanol, glacial acetic acid and ethanol were from Merck (Darmstad, Germany). Water was Milli-Q. All of the reagents were pro-analysis quality.

\section{Methods}

\section{Standard Solution preparation}

A stock solution of enalapril maleate was prepared in ethanol, to a concentration of $1 \mathrm{mg} \mathrm{mL}^{-1}$. A stock solution of enalaprilat was prepared in ethanol at $1 \mathrm{mg} \mathrm{mL}^{-1}$. Diketopiperazine degradation product was produced from standard of enalapril maleate according to the USP method. ${ }^{2}$

\section{Sample preparation}

Pharmaceutical preparations were tablets, nominally containing $10 \mathrm{mg}$ of enalapril maleate. 20 tablets were weighed and powered. A portion equivalent to $10 \mathrm{mg}$ of enalapril maleate was accurately weighed and transferred to a 50 $\mathrm{mL}$ volumetric flask and diluted with water to volume (final concentration of enalapril $200 \mathrm{ng} \mu \mathrm{L}^{-1}$ ). Then it was mixed with a vortex for $15 \mathrm{~s}$, filtered and centrifuged for $4 \mathrm{~min}$, and the supernatant was used for chromatography studies.

\section{Chromatographic conditions}

Chromatography was carried out on silica gel F254 HPTLC plates, previously washed with methanol and activated at $120^{\circ} \mathrm{C}$ during 20 minutes.

Sample application was done on $4 \mathrm{~mm}$ bands using an automatic ATS 3 device (Camag). Sample and standard application volumens were $1 \mu \mathrm{L}$ of each. Number of tracks depended of each assay. For the chromatographic development, 1-buthanol: glacial acetic acid: water $(12: 3: 5, \mathrm{v} / \mathrm{v})$ was used as mobile phase. The chamber was previously saturated. Migration distance was $8 \mathrm{~cm}$. Densitometry readings were carried out using a scanner 3 Camag spectrodensitometer assisted by a computer equipped with software winCATS 1.4.2, and a deuterium lamp was used as the radiation source. Determinations were performed at a wavelength of $207 \mathrm{~nm}$.

\section{Validation}

The parameters validated were linearity, detection limit, quantitation limit, repeatability, intermediate precision, accuracy and selectivity. ,16-18

Validation was performed in compliance with the international standards.

Stability-indicating capability of the HPLC assay/Stress testing

It was established by HPTLC analysis of all stressed samples and standard solutions of the main degradation products of enalapril (enalaprilat and diketopiperazine). The composition of the mobile phase was chose to optimize separation between enalapril and their degradation products.

Stress testing was carried out according to the $\mathrm{ICH}$ stability testing guidance. ${ }^{16}$

\section{Hydrolysis:}

It was established by forced decomposition of $5 \mathrm{~mL}$ of a solution of enalapril maleate $1 \mathrm{mg} \mathrm{mL}^{-1}$, with $10 \mathrm{~mL}$ of $0.1 \mathrm{~N}$ hydrochloric acid and 10 $\mathrm{mL}$ of $0.1 \mathrm{~N}$ sodium hydroxide. Samples were heated on a hot plate at $60^{\circ} \mathrm{C}$ for

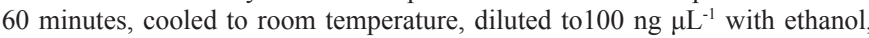
and analyzed.

\section{Oxidation:}

Oxidation of enalapril maleate was carried out in $3 \% \mathrm{H}_{2} \mathrm{O}_{2}$ at a concentration of $2 \mathrm{mg} \mathrm{mL}^{-1}$, at room temperature $\left(25 \pm 2^{\circ} \mathrm{C}\right)$ for 8 days and 80 ${ }^{\circ} \mathrm{C}$ for 6 hours, in the dark.

\section{Temperature:}

Solid enalapril maleate was exposed to dry heat at $50^{\circ} \mathrm{C}, 70^{\circ} \mathrm{C}$, and $100^{\circ} \mathrm{C}$, in an oven for 8 hours, taking samples each 2 hours. Samples were diluted with ethanol at $100 \mathrm{ng} \mu \mathrm{L}^{-1}$, and analyzed.

\section{Photostability:}

A solution of enalapril maleate $2 \mathrm{mg} \mathrm{mL}^{-1}$ in $1 \mathrm{~mm}$ layer in a petri-plate, was exposed to UV and VIS radiation for 3 hours. Samples were diluted with ethanol at $100 \mathrm{ng} \mu \mathrm{L}^{-1}$, and analyzed.

\section{Application of the method}

The method was used for quantitative determination of enalapril maleate in tablets.

\section{RESULTS AND DISCUSSION}

\section{Method validation}

Linearity

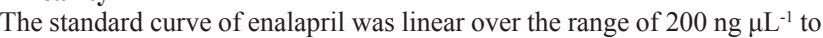
$1200 \mathrm{ng} \mu \mathrm{L}^{-1}$, which corresponded to $200 \mathrm{ng} / \mathrm{band}$ and $1200 \mathrm{ng} / / \mathrm{band}$, applying $1 \mu \mathrm{L}$ of each solution to the chromatographic plates. Concentration solutions of 200-400-600-800-1000 and $1200 \mathrm{ng} \mu^{-1}{ }^{-1}$ were analyzed. Each solution was spotted four times on one plate. Three replicates were used to establish the calibration plot and the correlation coefficient.The calibration plot relating the quantity of enalapril and peak area had a correlation coefficient of 0.998 , indicating a linear relationship over the range investigated.

\section{Detection and quantitation limits}

The detection limit (LOD) was $23.78 \mathrm{ng} / \mathrm{band}$ and the quantitation limit (LOQ) was $72.01 \mathrm{ng} /$ band, determined for three concentrations $(25,50$ and $150 \mathrm{ng} \mu \mathrm{L}^{-1}$ ), applying $1 \mu \mathrm{L}$ of each solution to the chromatographic plates, and using the equations: ${ }^{16-17} \mathrm{LOD}=3.3 \mathrm{~s} / \mathrm{b} ; \mathrm{LOQ}=10 \mathrm{~s} / \mathrm{b}$, where $\mathrm{s}$ is the standard deviation of the response and "b" corresponds to the slope obtained from the linearity study of the method.

\section{Precision}

The intra-assay precision was determined by analysis of solutions of

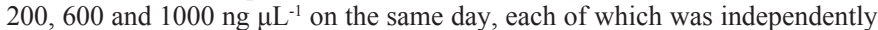
prepared and each of them being applied three times. ${ }^{2,16}$ Intermediate precision (inter-assay precision) analyses at the same concentrations for three different days.

Precision analysis studies showed an intra-assay variation between $1.14 \%$ and $1.43 \%$ and an inter-assay variation between $1.27 \%$ and $3.67 \%$ (Table 1 ).

Table 1. Precision of the method.

\begin{tabular}{|ccc|}
\hline \multicolumn{3}{|c|}{ Relative standard deviation (RSD) $/ \%$} \\
\hline $\begin{array}{c}\text { Concentration } \\
\left(\text { ng uL }^{-1}\right)\end{array}$ & $\begin{array}{c}\text { Intra-assay } \\
\text { precision }^{\mathrm{a}}\end{array}$ & $\begin{array}{c}\text { Intermediate } \\
\text { precision }^{\mathrm{b}}\end{array}$ \\
\hline 200.00 & 1.43 & 3.67 \\
600.00 & 1.58 & 3.16 \\
1000.00 & 1.14 & 1.27 \\
\hline
\end{tabular}

${ }^{a} n=27$; analyzed on the same day (three solutions of each concentration, three spots each)

${ }^{\mathrm{b}} \mathrm{n}=81$; analyzed on three different days (three solutions of each concentration, three spots each, prepared for 3 days)

\section{Accuracy}

The accuracy was determined by standard addition, applying the method to pharmaceuticals preparation $\left(200 \mathrm{ng} \mu \mathrm{L}^{-1}\right)$ to which known amounts of standard substance corresponding to $80 \%, 100 \%$ and $120 \%$ of the concentration expected in the samples were added. Three solutions of each concentration were prepared and three replicates were measured for each one. The accuracy was then calculated from the test results as the percentage of analyte recovered by the assay. The recovery obtained did not differ from the real value in more than $4.05 \%$ and is independent of the concentration with a minor coefficient of variation of $1.25 \%$ as shown in Table 2 .

\section{Selectivity}

The selectivity of the method was evaluated through possible interference due to degradation products. For that, a mixture of enalapril, enalaprilat and enalapril diketopipierazine (DKP) was prepared at a concentration of $100 \mathrm{ng}$ $\mu \mathrm{L}^{-1}$, for each compound. Values for Rf were 0.52 for enalaprilat, 0.62 for enalapril, and 0.82 for DKP, as shown at Figure 3 . 
Table 2. Method accuracy.

\begin{tabular}{cccc}
\hline $\begin{array}{c}\text { Actual concentration } \\
\left(\mathrm{ng} \mathrm{uL}^{-1}\right)\end{array}$ & $\begin{array}{c}\text { Found concentration } \\
\left(\mathrm{ng} \mathrm{uL}^{-1}\right)^{\mathrm{a}}\end{array}$ & Accuracy $\%^{\mathrm{b}}$ & $\mathrm{RSD} / \%^{\mathrm{c}}$ \\
\hline \multicolumn{4}{c}{ Intra-assay } \\
\hline 360.00 & $345.42 \pm 3.80$ & 95.95 & 1.10 \\
400.00 & $395.60 \pm 4.23$ & 98.90 & 1.07 \\
440.00 & $453.38 \pm 4.67$ & 103.04 & 1.03 \\
\hline & & & \\
\hline 360.00 & $348.12 \pm 4.35$ & 96.70 & 1.25 \\
400.00 & $398.96 \pm 4.47$ & 99.74 & 1.12 \\
440.00 & $452.32 \pm 4.84$ & 102.80 & 1.07 \\
\hline
\end{tabular}

${ }^{a}$ Each value is the mean \pm standard deviation.

${ }^{\mathrm{b}}$ (Founded concentration/ added concentration) x 100.

${ }^{\mathrm{c}}$ Relative standard deviation (coefficient of variation).

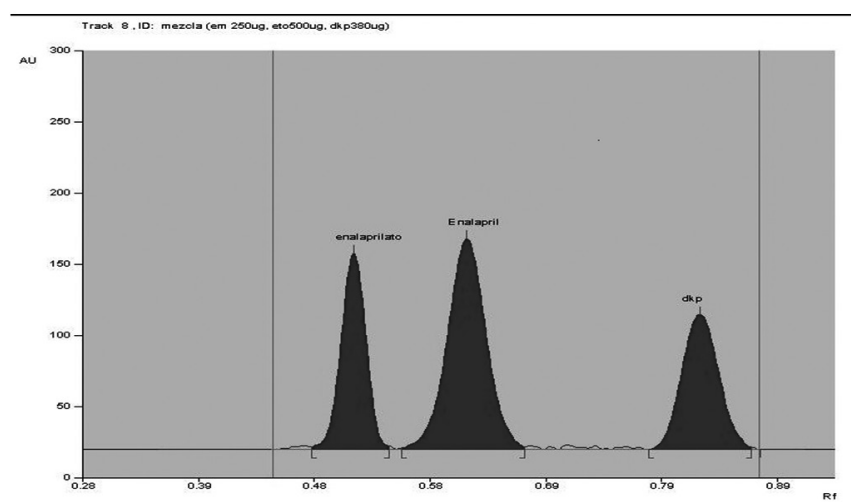

Figure 3. Selectivity of the method. Study with degradation products. Peak $n^{\circ}$ 1: enalaprilat; peak $n^{\circ} 2$ : enalapril; peak ${ }^{\circ} 3$ : DKP. Axis X: retarding factor/Rf. Axis Y: absorbance unit/AU.

Also, the selectivity between enalapril and hyrochlorotiazide, the more common compound in the commercial mixtures of enalapril, was studied. The Rf was 0.52 for enalaprilat, 0.62 for enalapril, and 0.83 for hydrochlorotiazide (Figure 4).

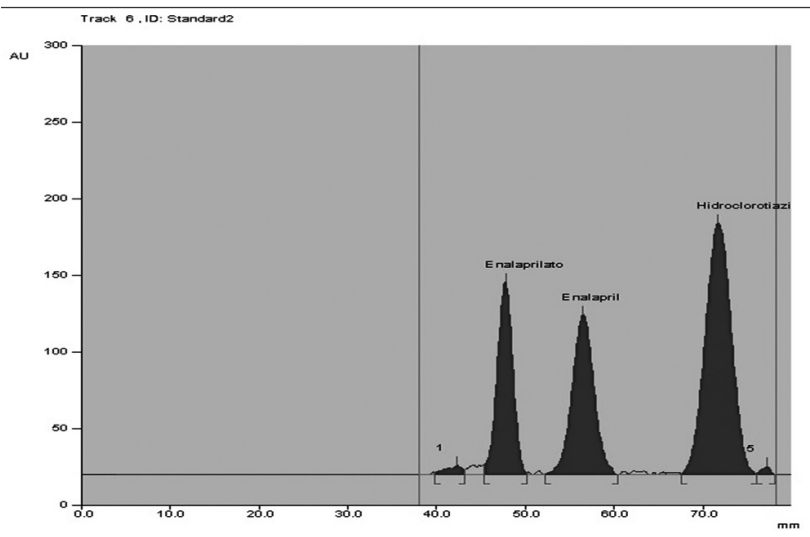

Figure 4. Selectivity of the method. Study with hydrochlorotiazide. Peak $\mathrm{n}^{\circ}$ 1: enalaprilat; peak $\mathrm{n}^{\circ} 2$ : enalapril; peak $\mathrm{n}^{\circ} 3$ : hydrochlorotiazide. Axis X: distance ran by the compound/mm. Axis Y: absorbance unit/AU.
Stability-indicating capability of the HPTLC assay/Stress testing

After treatment of enalapril with acid, none degradation product was found. However, after treatmen with basic, peaks of enalaprilat and DKP were observed, and also one minor peak. All of these peaks were resolved from enalapril (Figure 5). When the drug was exposed to a forced degradation with UV or sunlight, and to forced degradation with peroxide or with temperature $\left(50^{\circ} \mathrm{C}-70^{\circ} \mathrm{C}-100^{\circ} \mathrm{C}\right)$, no degradation product was found, during the time of the study. The degradation products for enalapril mentioned in the literature are enalaprilat and DKP. ${ }^{6,19-21}$

According to previous studies, enalapril degraded in various media, but we found degradation only under basic condition. This finding can be explain because the time of the study, and maybe with more time of drug exposition, degradation products could be find. In the hydrolysis study, samples were heated on a hot plate at $60^{\circ} \mathrm{C}$ for 60 minutes. In other study, total time for basic hydrolysis was 30 minutes, and total time for acid and neutral hydrolysis was 24 hours. ${ }^{22}$

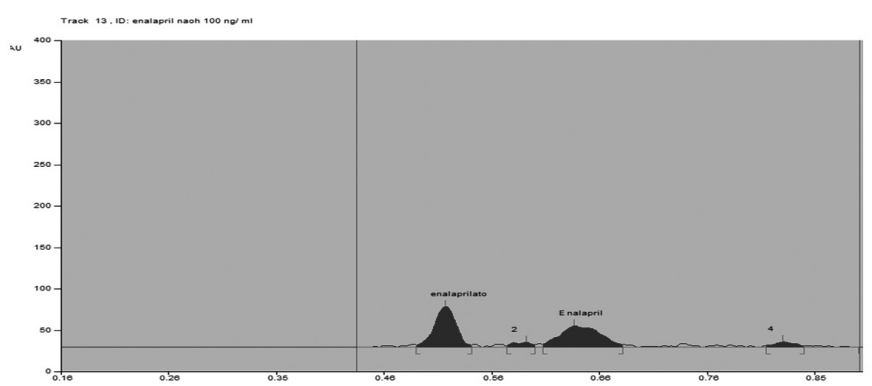

Figure 5. Study at forced degradation of enalapril with $0.1 \mathrm{~N} \mathrm{NaOH}$

Peak $n^{\circ} 1$ : enalaprilat; peak $n^{\circ} 2:$ ?; peak $n^{\circ} 3$ enalapril; peak $n^{\circ} 4$ : DKP. Axis $\mathrm{X}$ : retarding factor/Rf. Axis Y: absorbance unit/AU.

\section{Application of the method}

Table 3 shows the application of the method for quantitative determination of enalapril maleate in tablets by the proposed HPTLC method, using three different pharmaceutical products.

Table 3. Determination of enalapril in tablets.

\begin{tabular}{|c|c|}
\hline Product & Content of enalapril $(\%)^{\mathrm{a}}$ \\
\hline 1 & $100.05 \pm 3.25$ \\
\hline 2 & $97.00 \pm 3.30$ \\
\hline 3 & $93.50 \pm 3.38$ \\
\hline
\end{tabular}

${ }^{\text {a }}$ Mean \pm SD

\section{CONCLUSIONS}

A stability-indicating HPTLC assay method for the determination of the chemical stability of enalapril maleate has been developed and validated, with appropriate precision, sensibility, accuracy and selectivity.

The method is stability-indicating since it allows the determination of enalapril maleate in the presence of its degradation products. Therefore, the proposed HPTLC method can be useful for stability studies of enalapril maleate in tablets. None stability-indicating HPTLC method for enalapril was found in literature. HPTLC method developed and validated in this work resulted fast, simple, efficient and easy to perform. HPTLC separation was obtained within few minutes and the method allows for a large number of samples to be measured simultaneously with a very good accuracy, sensitivity and precision. It is very important, specially in quality control. Therefore, this method is novelty and allows a fast and reliable analysis.

\section{ACKNOWLEDGEMENTS}

The authors would like to thank the Research Council at the University of Concepción (Project DIUC n 204.074.034-1.0). 


\section{REFERENCES}

1.- Gennaro, A. Remington: the Science and Practice of Pharmacy, Lippincott Williams /Wilkins. 2000.

2.- The United States Pharmacopeia/ The National Formulary (USP 24/NF 19), United States Pharmacopeial Convection, Inc., 1999.

3.- Lund, W. The Pharmaceutical Codex, The Pharmaceutical Press.1994.

4.- Yoshioka, S., Stella, V. Stability of Drugs and Dosage Forms, Kluwer Academic Plenum Publishers. 2000.

5.- Stanisz, B. Acta Pol. Pharm., 415, 61, (2004)

6.- Lima, D., Dos Santos, L., Lima, E. J.Pharm.Biomed. Anal.47, 934, (2008)

7.- Baldessarini, R-J., Tarazi, F-I. In: Hardman,J., Limbird L., eds. Las Bases Farmacológicas de la Terapéutica, Mc Graw-Hill. 2003.

8.- Roskar, R., Simoncic, Z., Gartner, A., Kmetec, V. J.Pharm.Biomed. Anal. 49, 295, (2009)

9.- $\quad$ Fattah, A., Walilya, E., Belala, S., El.Heabab, E., El Kersbb, A. J.Pharm. Biomed. Anal. 13, 851, (1995)

10.- Al-Momani, F. Turk. J. Chem. 25, 49, (2001)

11.- Zoppi, A., Linares, M., Longhi, M. J.Pharm. Biomed. Anal. 37, 627, (2005)
12.- Manoranjani, M., Kamala, K. Int. J.Research Pharm. Biomed. Sci. 2,1651, (2011)

13.- Elmali, F., Alpdogan, G. Turk J. Chem. 27, 65, (2003)

14.- Mariusz, S., Máslanka, A., Jan, K. J.Liquid Chromatogr.\& Related Technol. 31, 1892, (2008)

15.- Kondawar, M., Gaikwad, R., Apate, V., Ravetkar, A. Int.J.Phar.Technol. Resesearch 3, 1454, (2011)

16.- The Sixth ICH Internacional Conference on Armonization of Technical Requirements for Registration of Pharmaceuticals for Human Use, Osaka, 2003.

17.- Shabir, G. J.Chromatogr .A 987, 57, (2003)

18.- FDA Reviewer Guidance Validation of Chromatographic Methods. CDER, 1994

19.- Delgado, J., Remers, W. Wilson and Gisvolds. Textbook of Organic Medicinal and Pharmaceutical Chemistry, Lippincott-Raeven, 1998.

20.- Mc Evoy, G. AHFS Drug Information; American Society of HealthSystem Pharmacists. 2006.

21.- Sweetman, S. Martindale, Guía Completa de Consulta Farmacoterapéutica, Pharma Editores S.L. 2003

22.- de Diego,M., Godoy, R., Godoy,C-G.,.Mennickent, S. Quimica Nova 34, $450,(2011)$ 